\title{
Photonics technician education in Michigan: an update
}

\section{Anca Sala}

Anca L. Sala, "Photonics technician education in Michigan: an update," Proc. SPIE 10741, Optics Education and Outreach V, 1074105 (14 September 2018); doi: 10.1117/12.2320632

SPIE Event: SPIE Optical Engineering + Applications, 2018, San Diego, California, United States 


\title{
Photonics technician education in Michigan: an update \\ Anca L. Sala* \\ Baker College, Flint MI, USA
}

\begin{abstract}
The only two-year program to educate photonics technicians in Michigan was introduced at Baker College in 2013. Graduates are employed with photonics companies in the state, fulfilling the primary mission of the program. The program curriculum was revised for this academic year with more curriculum enhancements planned, including photonics applications in autonomous vehicles such as LIDAR, and the use of high power lasers in manufacturing. Efforts to expand the program and create a more sustainable pipeline of students are under way with continued support from the National Science Foundation. These include the introduction of photonics content in Career and Technical Education high school programs. The paper will describe the updated program curriculum, the resources available in the Optics and Photonics Lab, and the collaborative and outreach activities with high schools in the state.
\end{abstract}

Keywords: Photonics education, optics, laser, technology, Michigan, college, photonics technician.

\section{INTRODUCTION}

Responding to a documented need for well-prepared photonics technicians in Michigan and across the United States, Baker College introduced a two-year Associate in Photonics and Laser Technology (PLT) program in fall 2013. The goal of the program is to provide students a solid theoretical foundation in optics, photonics, and lasers as well as handson laboratory skills with optical components and testing equipment. The program follows the model of two-year engineering technology programs dedicated to a specific area, in this case photonics. Other two-year programs exist around the country that insert one or two photonics courses in a more general engineering technology curriculum to provide students a basic knowledge of the field.

The initial development of the PLT program with support from OP-TEC ${ }^{1}$, the National Center for Optics and Photonics Education, Mi-Light ${ }^{2}$, the Michigan Photonics Cluster, and the National Science Foundation (NSF) was described in a previous paper $^{3}$. Several classes of students have graduated from the program since then and were hired by photonics companies in the state. A majority of these students were adults interested in a new career, with only a few high school graduates going directly into the college program.

The program curriculum underwent a substantial revision in fall 2017 when the College transitioned from a quarterbased to a semester-based schedule. At that time the Associate programs were standardized to a total of 60 credits and the Bachelor programs to a total of 120 credits, with a few exceptions. The PLT program had an equivalent of 70 semester credits in its quarter version, so it required elimination of 10 credits for the semester version. This was achieved in part by reducing the number of required general education credits in the curriculum. The technical content of the program was revised by not diminished in the process.

In addition, curriculum changes were made, and others are planned to keep the program current with the photonics applications used by the industry in the state and region. High power laser applications for materials processing in manufacturing are very prominent in Michigan and the Midwest. Another area of high interest in Michigan is the development of Advanced Driver Assistance Systems (ADAS) and autonomous vehicles. Photonics continues to provide a lot of innovation in this area through a variety of applications including adaptive headlights, Heads-Up Displays, and sensors such as cameras and LIDARs.

The paper describes the revised PLT program curriculum, the further development of laboratory resources, and also the efforts that are being made to ensure a pipeline of students coming into the program and their options to continue their education after the Associate degree.

*anca.sala@baker.edu; phone 1810 766-4111; fax 1810 766-4042; www.baker.edu

Optics Education and Outreach V, edited by G. Groot Gregory, Proc. of SPIE Vol. 10741, 1074105

(C) 2018 SPIE · CCC code: $0277-786 X / 18 / \$ 18 \cdot$ doi: 10.1117/12.2320632 


\section{PHOTONICS AND LASER TECHNOLOGY PROGRAM CURRICULUM AND LABORATORY RESOURCES}

\subsection{Program curriculum}

As described in the Introduction, the College transition to a semester schedule in fall 2017 provided the opportunity for a detailed review of the program curriculum resulting in several program improvement changes. Table 1 shows the credit hour changes in the areas that make up the curriculum. Credit reductions took place in the general education, basic electric circuits, and optics and photonics areas.

Table 1. Photonics and Laser Technology program curriculum in quarter and semester versions.

\begin{tabular}{|l|c|l|l|c|}
\hline Quarter System (Fall 2013 - Summer 2017) & \multicolumn{3}{|l|}{ Semester System (Fall 2017 - Present) } \\
\hline Area & $\begin{array}{l}\text { Quarter } \\
\text { Credits }\end{array}$ & $\begin{array}{l}\text { Semester } \\
\text { credits }\end{array}$ & Area & Credits \\
\hline General Education & 25 & 16.7 & General Education & 12 \\
\hline $\begin{array}{l}\text { Mathematics and } \\
\text { Physics }\end{array}$ & 16 & 10.7 & Mathematics and Physics & 11 \\
\hline Basic Electric Circuits & 20 & 13.3 & Basic Electric Circuits & 8 \\
\hline & & & Robotics & 3 \\
\hline Optics and Photonics & 36 & 24.0 & Optics and Photonics & 20 \\
\hline $\begin{array}{l}\text { Computer Aided } \\
\text { Design }\end{array}$ & 4 & 2.7 & Computer Aided Design & 3 \\
\hline Internship/Co-op & 4 & 2.7 & Internship/Co-op & 3 \\
\hline Total quarter credits & $\mathbf{1 0 5}$ & $\mathbf{7 0 . 0}$ & Total semester credits & $\mathbf{6 0}$ \\
\hline
\end{tabular}

Details about the curriculum changes in the technical areas are as follows. The basic electric circuits area included DC and AC circuits, digital circuits, and solid state devices courses. The latter two courses were eliminated, and a robotics course was introduced. The faculty committee found the more applied robotics course to be an important addition to the curriculum due to the widespread application of robotics and automation in the industry in the state and region, including in photonics related applications.

The optics and photonics area included separate courses in Geometrical Optics and Wave Optics, which were taught after the first year Introduction to Photonics and Laser Technology course. The two optics foundation courses were eliminated but the introductory course was expanded to include more content in those areas. Consequently, the course requires more lecture and laboratory time, translating into more credits. Two courses were dedicated to lasers in quarter version, Laser Fundamentals and Laser Systems. These were consolidated in one 4-credit course, Laser Systems.

The Optical Systems Analysis course has been renamed Optical Components, Systems and Metrology to better capture the content of the course. The Fiber Optics and Data Communications, Photonics Applications, and Capstone Project courses have not been changed other than adjusting from 10 weeks of instruction per quarter to 16 weeks per semester.

The Photonics Applications course is intended to provide students knowledge about applications of photonics in various areas, including manufacturing, health and medicine, defense and homeland security, and energy. The course consists of a series of modules dedicated to each area. In order to keep the course relevant and current, the choice of modules is flexible. At this time with support from the National Science Foundation Advanced Technological Education program the author is working on developing modules focusing on robot assisted laser materials processing, photonics in automotive, and integrated photonics. These modules will be introduced in the Photonics Applications course.

\subsection{Photonics in Automotive Educational Module}

This module discusses several photonics applications relevant to current developments in the automotive industry, such as ADAS and autonomous vehicles. A special focus of the module is on sensors, in particular LIDAR. The high market growth predictions, shown in Fig. 1, and the intense competition to develop a high performing as well as inexpensive sensor indicate that LIDAR will be an important application, with multiple areas of use including autonomous vehicles, aerospace, agriculture, construction, wind farms and others. 


\section{LiDAR market forecast by application}

(Source: LiDARs for Automotive and Industrial Applications report, Yole Développement, May 2018)

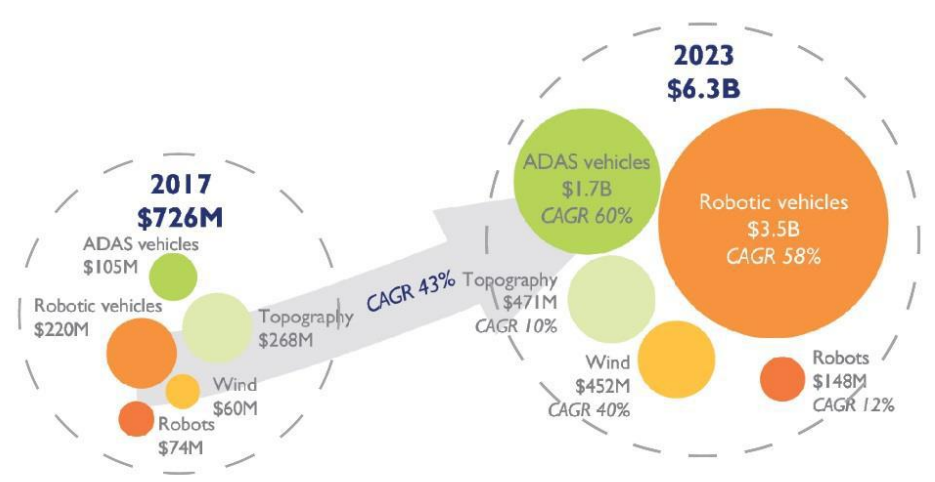

Figure 1. LIDAR market forecast by application, from reference ${ }^{4}$.

The module explains the principle of operation of LIDAR, its characteristic parameters, capabilities, and trade-offs. Different types of LIDARs and their components are presented, including mechanically scanned, micromirror beam steering, flash, solid state, and Frequency Modulated Continuous Wave (FMCW). The current state of development and products from various companies developing LIDAR for automotive applications are discussed.

Other photonics applications discussed in this module include: adaptive headlamps that adjust the beam depending on the driving situation, cameras for day time and night time driving, interior lighting with LED and fiber optics, Heads-Up Displays, and optical communications in automotive. A separate module will focus on robot assisted high power laser material processing operations.

\subsection{Laboratory Resources}

With the exception of the Photonics Applications course, all optics and photonics courses in the curriculum include a laboratory component. The Optics and Photonics Laboratory was created at the beginning of the program and has continued to add equipment as the program has evolved. The equipment available can be categorized as follows:

- Optics education kits for teaching the Introduction to Photonics and Laser Technology course: OEK-STD kits from Newport and kits developed by MPEC ${ }^{5}$, Midwest Photonics Education Center, a National Science Foundation Advanced Technological Education (ATE) regional Center. Components included in each kit are mirrors, lenses, prisms, waveplates, beam splitters, pinholes, diffraction gratings, stages, posts, mounts, and a 2'x2' optical breadboard.

- Lasers: HeNe lasers with powers from $2 \mathrm{~mW}$ to $10 \mathrm{~mW}$, diode lasers, multiwavelength argon ion lasers, Nd:YAG lasers with frequency doubling and Q-switch units, two fiber lasers with powers $400 \mathrm{~W}$ and $1 \mathrm{~kW} . \mathrm{A} \mathrm{CO}_{2}$ laser is available as part of a laser cutter/engraver. Safety glasses for all types of lasers are available.

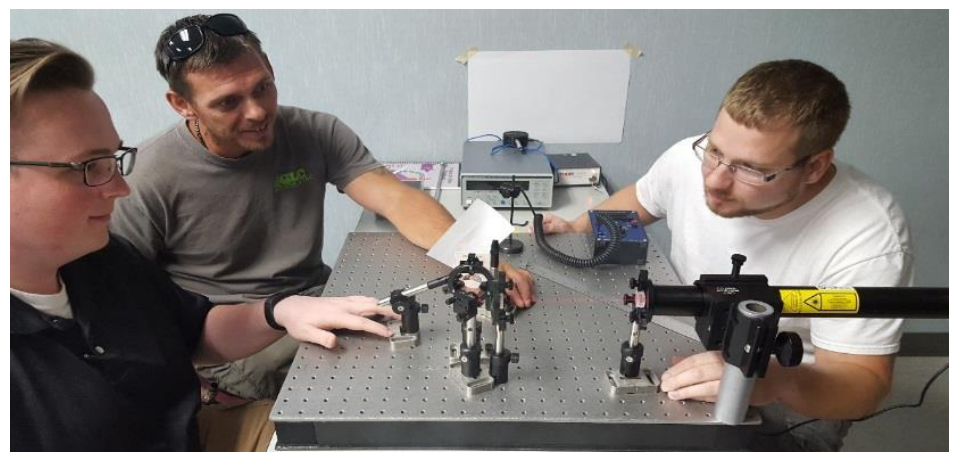

Figure 2. Students working in the Optics and Photonics Laboratory. 
- Test equipment: optical power meters and detectors for powers up to $1 \mathrm{~kW}$, beam profiling cameras, spectrometers, and shearing interferometers.

- Fiber optics: variety of optical fibers and cables, connectors, fiber inspection scopes, and optical power meters.

- Optical waveguide: optical waveguiding, WDM component characterization, DWDM system characterization, Bragg grating characterization, eye diagram and BER testing units.

With the introduction of LIDAR content in the curriculum, LIDAR sensors will be acquired to support lab experiments and supplement the theoretical material. A hobby device from Scanse has been used so far to illustrate the basic concepts. Figure 3 shows the 2D output of the sensor. A 3D image can be obtained by mounting the sensor on a rotating base.

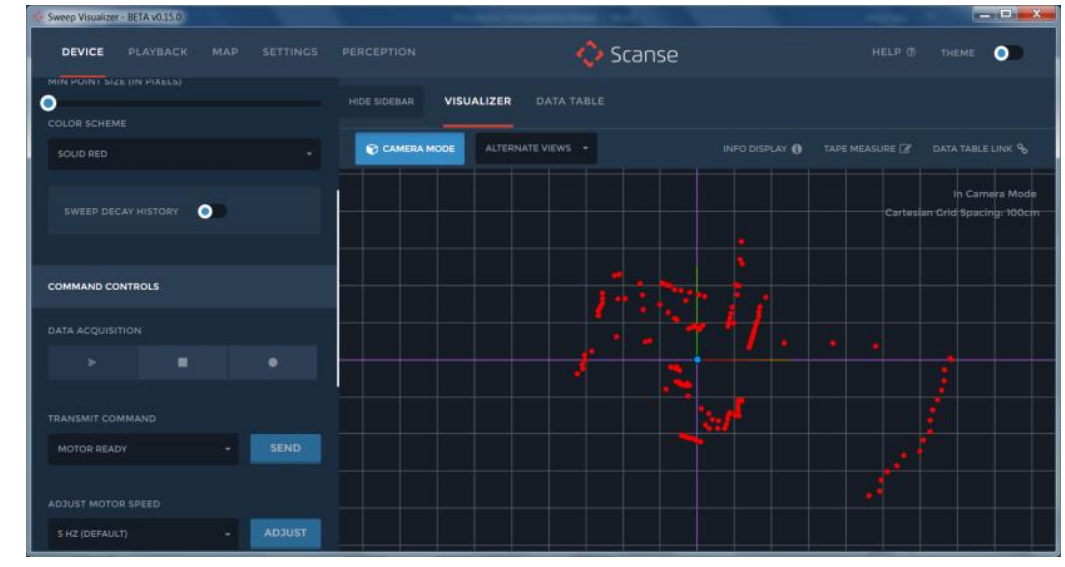

Figure 3. Single plane mapping with Scanse hobby LIDAR sensor.

A second laboratory for the PLT program is currently under construction. The Advanced Laser Applications Lab will allow us to teach experimental skills in the area of high power laser materials processing at a level comparable to current industry processes. We envision the lab to be used for delivering program curriculum, projects including the Capstone Project, non-credit training, as a showcase during events and visits to the College, and for collaboration on research projects that require a high power laser. The two key components for the new lab are a $1 \mathrm{~kW}$ fiber laser from IPG Photonics, model YLS-1000, and a 6-axes high payload ABB robot, model IRB-1600. The lab will have its own dedicated space with all the safety measures required. Construction is expected to be completed in the next two months.

\section{COLLABORATIVE AND OUTREACH ACTIVITIES}

\subsection{Outreach activities}

One of the more challenging aspects of offering a two-year photonics technology college program is ensuring a pipeline of students to enroll in and complete the program. Even though photonics applications are everywhere and are encountered in every day life, awareness of rewarding careers for photonics and laser technicians is lacking in the public. In the Baker College program, we have had more non-traditional students enrolling than high school graduates. However, the enrollment of non-traditional students in technology-oriented college programs seems to be affected by factors such as availability of jobs and unemployment rate at a given time. There are of course many other variables that come into play when looking at the enrollment of students in two-year college programs ${ }^{6,7}$.

In order to increase awareness, since the start of the program we have delivered numerous outreach activities targeting mostly high school students, but also middle school and even elementary school students. These included presentations from faculty members given at the K - 12 schools, Open Houses, visits and summer camps for K - 12 students at Baker College, participation in outside public events such as summer festivals and car shows, and others. In a majority of events, we have strived to make them as interactive as possible so that participants can have a direct hands-on experience of optics and photonics phenomena. Outreach activities that took place during the 2015 International Year of Light in Michigan were described in a previous paper ${ }^{8}$. 
Through the generous support of SPIE we were able to offer a new outreach activity to several middle schools in southeast Michigan this spring. About 600 students had the opportunity to learn about lasers and then enjoy the excellent Prismatic Laser Show in celebration of the International Day of Light 2018. Outreach activities will continue as an integral part of offering the PLT program. The next event we will participate in will be the Back-to-the-Bricks car festival in August. This will be the fourth year of participation by Baker College and the Optics Students at the University of Michigan (OSUM) group in this large event taking place annually in the city of Flint.

Also new in spring 2018 was the first annual Baker College Photonics Symposium. The event was envisioned to bring together the photonics community at large with participation from high school students, teachers, and counselors. The speakers represented a broad spectrum, from industry to academia, with presentations covering the range from technology to research to photonics career exploration. The Photonics Symposium is intended to be an annual event, with a goal of increasing participation every year.

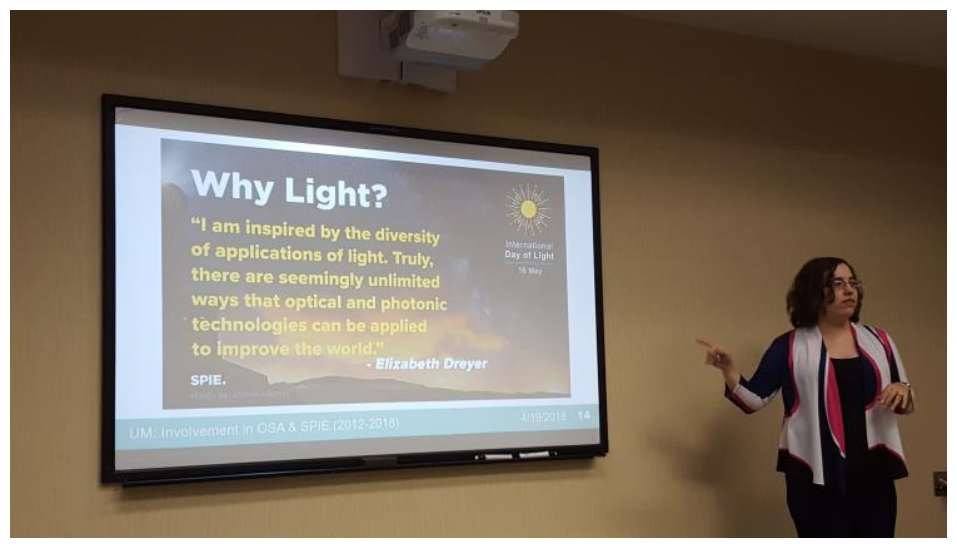

Figure 4. Photonics career presentation at the Photonics Symposium, April 19, 2018.

\subsection{Collaborative activities}

In 2017 Baker College received a second NSF ATE grant to continue to develop and grow the PLT program. One of the objectives of the grant aims to create a more direct route from high school to the college program, by introducing photonics topics in the curriculum of Career and Technical Education (CTE) programs taught in the state, with the ultimate goal of creating a Photonics CTE program. At this time the existing Engineering and Mechatronics CTE programs have been identified as appropriate for adding photonics topics. The Engineering program provides students with broad knowledge of engineering and engineering technology using a project approach. Students complete a series of projects throughout the year chosen from different engineering disciplines. The Mechatronics program provides student knowledge and hands-on skills from areas such as machining, welding, electric circuits, programmable logic control, and robotics. Professional development for CTE teachers in the form of workshops delivered in the Optics and Photonics Lab at Baker College is planned to support them with the introduction of photonics in the curriculum. Depending on the amount of material they will be able to include, college credit can be given for the Introduction to Photonics and Laser Technology course.

Another component of the grant objective described above is creating articulation agreements between the PLT program and 4-year Bachelor in Engineering Technology programs. Four-year programs offered in Michigan that can provide such a pathway include Manufacturing Engineering Technology and Electronic Engineering Technology. The first is more general and can offer a $2+2$ path for students, while the second is more specialized and will require more than two years to complete for graduates of the Baker College PLT program. Some graduates are also interested in 4-year BS Engineering programs such as Electrical Engineering. For this pathway the general education courses and only a few technical courses transfer, extending the time needed to complete the degree.

The industry in the state has continued to support the program by participating in Advisory Board meetings, offering internships to students in the program, hiring our graduates, and providing donations and equipment support. The industry continues to express an unmet need for well-prepared photonics technicians, which goes beyond the state of Michigan. 


\section{CONCLUSIONS AND FUTURE STEPS}

The two-year Photonics and Laser Technology program offered by Baker College is now well-established. Its curriculum has been revised and streamlined, with new courses and topics added and others planned to be introduced. The Optics and Photonics Laboratory added new equipment providing very good resources for teaching the hands-on skills needed by the industry. A new lab, the Advanced Laser Applications Lab, is currently under construction extending the range of experimental capabilities at the College. Numerous outreach activities continue to take place, a highlight being the first annual Photonics Symposium held at the College this spring.

A challenge area continues to be attracting high school graduates and others to enroll in the PLT program. Work is being done in order to introduce photonics in high school curricula, particularly in Career and Technical Education programs

which enroll students interested in hands-on technology oriented careers.

\section{ACKNOWLEDGMENTS}

This paper is based upon work supported, in part, by the National Science Foundation Advanced Technological Education program, under Grant DUE \# 1700599. Any opinions, findings, and conclusions or recommendations expressed in this material are those of the author and do not necessarily reflect the views of the National Science Foundation. In addition to the National Science Foundation, support from SPIE, OP-TEC, and Mi-Light is gratefully acknowledged.

\section{REFERENCES}

[1] OP-TEC, the National Center for Optics and Photonics Education, www.op-tec.org

[2] Mi-Light, The Michigan Photonics Cluster, www.mi-light.org

[3] Anca L. Sala, "Developing a photonics education program at college level from the ground up", Proceedings of SPIE Vol. 9188 (2014)

[4] Yole Developpement, "LiDARs: many technologies, many players, lots of investments... What will be the next step?” (2018), http://www.yole.fr/Lidar_MarketOverview_AutomotiveFocus.aspx\#.W0ufZ9VKj3g

[5] MPEC Midwest Photonics Education Center, http://www.midwestphotonics.org/

[6] Noel-Levitz, "Why Did They Enroll? The Factors Influencing College Choice”, National Research Report (2012).

[7] Aaaron Keith McCullough, "Factors That Impact Two-Year College Attendance and Program Enrollment among Community College Students", Ph. D. Dissertation (2010).

[8] Anca L. Sala et all, "Celebrating the International Year of Light in Michigan", Proceedings of SPIE Vol. 9946 (2016) 